\title{
Socio-Demographic Factors Associated with Psychoactive Substance Use among Commercial Motorcycle Operators in Kano, Nigeria
}

\author{
Mustapha Ibrahim Gudaji1,2*, Zahraddeen Garba Habib ${ }^{1,2}$ \\ ${ }^{1}$ Department of Psychiatry, Faculty of Clinical Sciences, College of Health Sciences, Bayero University, \\ Kano, Nigeria \\ ${ }^{2}$ Aminu Kano Teaching Hospital, Kano, Nigeria \\ Email: *mgudaji@yahoo.com,zghabib@yahoo.com
}

Received 23 November 2015; accepted 16 January 2016; published 19 January 2016

Copyright (C) 2016 by authors and Scientific Research Publishing Inc. This work is licensed under the Creative Commons Attribution International License (CC BY). http://creativecommons.org/licenses/by/4.0/

\section{(c) (i) Open Access}

\begin{abstract}
Background: Psychoactive substance use was common among commercial motorcycle operators. Studies had shown that there were some socio-demographic factors which were commoner among commercial motorcycle operators who used psychoactive substances. However, this was not explored among commercial motorcycle operators in Kano, North Western Nigeria. Aim: The aim of the study was to determine the socio-demographic factors associated with psychoactive substance use among motorcycle operators in Kano, Northwestern Nigeria. Methods: It was a cross-sectional study. Instrument used for data collection included socio-demographic questionnaire and World Health Organisation Student Drug Use Questionnaire. Data analysis was done using Statistical Package for Social Sciences (SPSS) 16th edition. Results: Commercial motorcycle operators who used substances were found to be of younger age group $\left(X^{2}=10.9, P<0.001\right)$, single $\left(X^{2}=4.3, P=0.034\right)$ and had a father who used tobacco $\left(X^{2}=4.28, P=0.04\right)$. Participants who were single were more likely to use inhalants $\left(X^{2}=21.06, P=0.001\right)$, opiates $\left(X^{2}=11.82, P=0.012\right)$, cannabis $\left(X^{2}=5.12, P=\right.$ 0.028) and stimulants $\left(X^{2}=5.12, P=0.028\right)$ compared to those who were married. Conclusion: This study found that being of younger age, being single, and having a father who smoked were significantly associated with psychoactive substance use. Participants who were singles were more likely to use inhalants, opiates, cannabis and stimulants. No relationship was observed between the age of the respondents and specific substance use. Legislations should be enacted to reduce the rate of psychoactive substance use among motorcycle operators and general population at large.
\end{abstract}

\footnotetext{
*Corresponding author.
}

How to cite this paper: Gudaji, M.I. and Habib, Z.G. (2016) Socio-Demographic Factors Associated with Psychoactive Substance Use among Commercial Motorcycle Operators in Kano, Nigeria. Open Journal of Psychiatry, 6, 76-85. 


\section{Keywords}

\section{Psycho-Active Substance, Sociodemographic Factors, Motorcycle Operators, SDUQ, Nigeria}

\section{Introduction}

In Nigeria, there has been a growing trend in the use of psychoactive substances. Current data indicate that drug use cuts across diverse groups, with high risk groups including males aged 10 to 29 years, law enforcement agents, commercial sex workers (CSW), commercial drivers and motor park touts [1]-[3]. However, studies in this area are limited in North Western Nigeria.

Several international studies highlighted the socio-demographic factors associated with psychoactive substance use. In Finland, in a nationwide survey of adult population, using a self-administered questionnaire, Kontula and his colleagues reported that in comparison with other European countries, drug use among the Finns was less prevalent, although there was a high prevalence of multiple drug use among the population studied [4].

A survey in the United States showed that $37 \%$ of the population reported using one or more illicit substances in their lifetime [5]. Thirteen percent had used the substance in the past 12 months and $6 \%$ had used them in the month before the survey. More than $66 \%$ of the people aged 12 to 25 years had used a psychoactive substance, and more than $15 \%$ of the United States population older than 18 years of age had serious substance use problems.

One United States population survey reported a 2\% lifetime prevalence use of amphetamine. Those aged 18 to 25 years reported the highest level of use, with 9\% reporting use at least once and $1 \%$ described themselves as current amphetamine users [6].

In North Africa, cannabis resin (hashish) had been traditionally used by members of the Sufi sect, while in East Africa, the use of khat was reported to be common. Cannabis (dagga) had been widely cultivated and used in South Africa [7]. Khat chewing was a social, culture based activity and some religious leaders were involved in the habit. High incidence of Khat chewing had been reported among university teachers, parents and other highly placed people in Ethiopia [8].

In a nationwide study of psychoactive substance use among adults in five of the six geopolitical regions of Nigeria, Gureje et al. reported that the prevalence of alcohol was $58 \%$, tobacco $17 \%$, sedatives $14 \%$, stimulants $2.4 \%$ and cannabis $3 \%$ among the population studied [3]. However, the study was limited to self-report assessment of substance use among the respondents.

In a review of psychoactive substance related cases admitted to the Department of Psychiatry Ahmadu Bello University Teaching Hospital (ABUTH), Kaduna, in the 80's it was reported that those aged 31 years and over tended to abuse alcohol, with majority being married [2] [9]. The studies reported that the combined use of alcohol with cannabis was more likely than combining cannabis with amphetamines.

Many studies of psychoactive substance use in Nigeria had been conducted on student populations. Students constituted a large portion of youths in Nigeria. Studies of drug use had indicated that the prevalence of drug use was high among the students population [10] [11].

The most commonly used psychoactive substances among university students had been reported to be salicylate analgesics (78\%), alcohol was next (42\%), stimulants, hypno-sedatives and cigarettes accounted for 35\%, $18 \%$ and $11 \%$, respectively [12].

Various sentinel studies in the country reported that the prevalence of alcohol and other substance use among students' population was high [13] [14]. Nevadomsky, in a study of drug use among secondary students in southern Nigeria, reported a prevalence of alcohol use to be $65 \%$, tobacco $24 \%$ [15]. The author reported that use of benzodiazepines, cannabis and amphetamines among the subjects were less common.

Vázquel, in a study of prevalence of psychoactive substance use and dependence among Spanish university students, reported that $86.5 \%$ had consumed psychoactive substances, and 10.5\% satisfied DSM IV criteria for dependence on nicotine, alcohol, caffeine or cannabis [16].

Mason et al., in a study of substance use, social networks, and the geography of urban adolescents in Washington, USA, reported a prevalence of psychoactive substance use among the respondents as $65 \%$ [17]. The au- 
thors reported that most popular psychoactive substances used were alcohol, cannabis and cocaine. Tobacco was not measured in the study as a primary psychoactive substance as some participants (18 years and older) can legally use it.

Centre for Disease Control and Prevention (CDC), reported a high prevalence of cannabis use (19.6\%) among teenagers aged 16 to 19 years [18]. Substance Abuse and Mental Health Services Administration (SAMHSA), reported a high prevalence of cannabis use (12.8\%) among young adults aged 18 to 25 years [19].

In Tanzania, Kalula, in a qualitative study of cannabis use among young people, reported an increasing trend of cannabis use among youths aged 15 to 25 years with a prevalence rate of 5\% [20].

Adebiyi et al., in a study of tobacco use among out of school adolescents aged 10 to 19 years in Ibadan, Southwestern Nigeria, reported a prevalence of tobacco use as $20.5 \%$ [21]. However, the study was limited to tobacco use.

Information on the use of psychoactive substances among motorcyclists in Nigeria and more specifically in Northern Nigeria is limited. The current study aims to determine the socio-demographic characteristics of psychoactive substance users among commercial motorcycle operators in a selected local council Area in Kano, Nigeria.

We hypothesized that the socio-demographic characteristics of psychoactive substance users among commercial operators in Kano will be similar to what is found in other parts of Nigeria and the world.

\section{Methodology}

The study was descriptive, cross-sectional and was carried out among 394 registered commercial motorcycle operators who were selected using multistage sampling technique in Tarauni Local Government Area of Kano State. Prior to the study, ethical clearance was obtained from the Research Ethical Committee of Aminu Kano Teaching Hospital. The National Patron of Amalgamated Commercial Motorcycle Owners and Riders Association of Nigeria (ACOMORAN) also gave permission for the study. Informed consent was also obtained from each of the participants in the study before administering study questionnaires.

The sample size was calculated using prevalence of substance use of 34.3\% obtained from a previous community based study in Kano city conducted by the Community Medicine Department of the AKTH. The sample size calculated was 338. However the sample size was increased to 400 which was about $20 \%$ for greater precision.

\section{Instrument for Data Collection}

\subsection{The WHO Student Drug Use Questionnaire (SDUQ)}

The WHO student drug use questionnaire (SDUQ), also known as youth survey questionnaire was adapted for this study. The questionnaire was developed by the WHO in cooperation with the United Nations Fund for Drug Abuse Control, for use in different socio-cultural settings [22]. The original questionnaire is made up of 22 items.

\subsection{Socio-Demographic Characters}

1) Item on age was retained, while item on sex was discarded, as the study was conducted on male respondents only, as commercial motorcycle operation is a male business at least in Kano City.

2) The item "How many years of school have you completed?" was retained and "How long have you being as commercial motorcycle operator” was introduced.

3) The items asking if the respondent was a student, full-time or part-time, for most of the last 12 months was a discarded, and, other item asking if the respondent is a commercial motorcycle operator, full-time or parttime, for most of the last 12 months, and whether the respondent has been a commercial motorcycle operator elsewhere was introduced.

4) Other items were added to elicit information on:

a) Respondent's marital status, number of wives and children, religion and participation in religious activities;

b) Level of education and occupation of respondent's parents;

c) Whether or not respondent's parents smoke cigarette or take alcoholic drinks. 


\subsection{Drug Abuse}

All the core items on drug abuse were retained.

\subsection{Procedure}

The data was collected between November and December 2009. Daily visit was paid to each of the selected motorcycle stands in the LGA, with assistance of the ACOMORAN chairman and his team, one ward a week. Two wards with larger number of participants required a second week visit of data collection. Specific visitation week was allocated to each of the wards. The motorcycle operators who were in their stand, who met the inclusion criteria, were administered the socio-demographic data and SDUQ. The questionnaires were interviewer administered, and anonymous. An average of ten interviews was conducted daily (with range of six to 14 interviews).

\subsection{Data Analysis}

Data analysis was done with the Statistical Package for the Social Sciences (SPSS), 16th edition. Simple descriptive data were presented with frequencies, proportions and percentages.

Continuous variables and categorical (nominal) variables were compared with student t-test and $X^{2}$ test respectively. All tests were two tailed, with $p$ value $<0.05$ taken as significant.

Table 1 shows the distribution of the participants according to socio-demographic variables. There were 394

Table 1. Sociodemographic characteristics of subjects.

\begin{tabular}{|c|c|c|}
\hline \multicolumn{3}{|c|}{ Total $N=394$} \\
\hline Variable & $\mathbf{n}$ & $\%$ \\
\hline \multicolumn{3}{|l|}{ Age group (yrs) } \\
\hline $22-30$ & 180 & 45.7 \\
\hline $31-38$ & 140 & 35.5 \\
\hline $39-47$ & 64 & 16.3 \\
\hline $48-55$ & 9 & 2.2 \\
\hline $56+$ & 1 & 0.3 \\
\hline \multicolumn{3}{|c|}{ Range $=22-60 ;$ Mean $=32.7 \pm 6.6$} \\
\hline \multicolumn{3}{|l|}{ Educational level } \\
\hline None & 31 & 7.9 \\
\hline Primary (completed) & 133 & 33.8 \\
\hline Secondary (completed) & 158 & 40.1 \\
\hline Higher education (completed) & 72 & 18.3 \\
\hline \multicolumn{3}{|l|}{ Marital status } \\
\hline Single & 45 & 11.3 \\
\hline Married & 349 & 88.7 \\
\hline \multicolumn{3}{|l|}{ No. of wives } \\
\hline 1 & 306 & 77.7 \\
\hline 2 & 40 & 10.2 \\
\hline 3 & 3 & 0.8 \\
\hline \multicolumn{3}{|l|}{ No. of children } \\
\hline $1-5$ & 239 & 60.6 \\
\hline$\geq 6$ & 76 & 19.3 \\
\hline
\end{tabular}


participants, aged 22 to 60 years, with mean age of 32.7 years \pm 6.6 . The modal age group was 22 - 30 years. Majority of the participants had some level of education, with about 9 in 10 having completed at least primary education. One hundred and fifty eight (40.1\%) of the participants had completed secondary education, 72 (18\%) had completed higher education (diploma and NCE). Three hundred and forty nine (88.7\%) of the respondents were married, with 306 (77.7\%) being married to one wife and the majority of them had between 1 to 5 children.

All the respondents were males and Moslems, who participate (>90\%) regularly in their religious activities.

The lifetime and current use of psychoactive substances are presented in Table 2. Tobacco had the highest prevalence for lifetime and current use with 76 respondents (19.3\%) and 63 respondents (16\%) respectively. This is followed by stimulant use, with lifetime use of 47 respondents (11.9\%), and current use with 41 respondents (10.5\%).

There was no reported use of alcohol, heroin, cocaine and benzodiazepines among the respondents.

Table 3 shows the relationship between age, marital status and education level of respondents by current substance use status. Among the psychoactive substance users, the younger respondents (22 - 35 years) were more likely to use psychoactive substances compared to the older respondents of $>35$ years (24.2\% vs. 10.1\%). This relationship was found to be statistically significant $\left(X^{2}=10.9, P<0.001\right)$.

Two in three of participants who were singles use psychoactive substances compared to 1 in 10 of married participants. The relationship was statistically significant $\left(X^{2}=4.3, P=0.034\right)$.

There was no relationship between education level and psychoactive substance use $\left(X^{2}=11.4, P=0.75\right)$. However, participants with higher levels of education generally reported less substance use compared to those with lower levels of education.

Table 4 shows the relationship between current use of specific psychoactive substances and age group of respondents. There was no statistically significant relationship between current specific substance use and age of the participants.

Table 5 shows the relationship between current specific psychoactive substance use and marital status of respondents. Inhalants $\left(X^{2}=21.06, P=0.001\right)$, opiates $\left(X^{2}=11.82, P=0.012\right)$, cannabis $\left(X^{2}=5.12, P=0.028\right)$

Table 2. Prevalence of substance use among respondents.

\begin{tabular}{cccccc}
\hline & \multicolumn{2}{c}{ Total $\mathbf{N}=\mathbf{3 9 4}$} \\
\hline Variable & $\begin{array}{c}\text { Tobacco } \\
\mathbf{n}(\%)\end{array}$ & $\begin{array}{c}\text { Stimulants } \\
\mathbf{n}(\%)\end{array}$ & $\begin{array}{c}\text { Cannabis } \\
\mathbf{n}(\%)\end{array}$ & $\begin{array}{c}\text { Inhalant } \\
\mathbf{n}(\%)\end{array}$ & $\begin{array}{c}\text { Opiates } \\
\mathbf{n}(\%)\end{array}$ \\
\hline Lifetime use & $76(19.3)$ & $47(11.9)$ & $15(3.8)$ & $8(2.0)$ & $5(1.3)$ \\
Current use & $63(16.0)$ & $41(10.5)$ & $13(3.3)$ & $7(1.8)$ & $5(1.3)$ \\
\hline
\end{tabular}

Table 3. Relationship between age, marital status and education level of respondents compared with current substance use status.

\begin{tabular}{|c|c|c|c|c|}
\hline \multirow[b]{2}{*}{ Variable } & \multicolumn{2}{|c|}{ Drug use } & \multicolumn{2}{|c|}{ Statistics test } \\
\hline & Users & Non users & $X^{2}$ & $P$. value \\
\hline Age (years) & n (\%) & n (\%) & & \\
\hline $22-35$ & $64(24.2)$ & 201 (75.8) & & \\
\hline$>35$ & $13(10.1)$ & 116 (89.9) & 10.9 & $<0.001^{*}$ \\
\hline \multicolumn{5}{|l|}{ Marital status } \\
\hline Single & $54(63.5)$ & $31(36.5)$ & & \\
\hline Married & $23(7.4)$ & $286(92.6)$ & 4.3 & $0.034^{*}$ \\
\hline \multicolumn{5}{|l|}{ Education } \\
\hline Primary (completed) & $36(22.0)$ & $128(78.0)$ & & \\
\hline Secondary (completed) & 33 (20.9) & 125 (79.1) & & \\
\hline Higher (completed) & $8(11.1)$ & $64(88.9)$ & 11.4 & 0.75 \\
\hline
\end{tabular}

Note: ${ }^{*}=$ Statistically significant. 
Table 4. Relationship between current specific substance use and age of respondents.

\begin{tabular}{|c|c|c|c|c|}
\hline \multirow[t]{2}{*}{ Substance } & \multicolumn{2}{|c|}{ Age (years) } & \multicolumn{2}{|c|}{ Statistics test } \\
\hline & $22-35$ & $>35$ & $X^{2}$ & $P$. Value \\
\hline Tobacco & n (\%) & n (\%) & & \\
\hline Users & $53(20.0)$ & $23(17.8)$ & & \\
\hline Non users & $212(80.0)$ & $106(82.2)$ & 0.26 & 0.36 \\
\hline \multicolumn{5}{|l|}{ Stimulant } \\
\hline Users & 34 (12.8) & $13(10.1)$ & & \\
\hline Non users & $231(87.2)$ & 116 (89.9) & 0.63 & 0.27 \\
\hline \multicolumn{5}{|l|}{ Cannabis } \\
\hline Users & $7(2.6)$ & $8(6.2)$ & & \\
\hline Non users & 258 (97.4) & 121 (93.8) & 3.0 & 0.08 \\
\hline \multicolumn{5}{|l|}{ Inhalants } \\
\hline Users & $5(1.9)$ & $3(2.3)$ & & \\
\hline Non users & $260(98.1)$ & $126(97.7)$ & 0.08 & 0.52 \\
\hline \multicolumn{5}{|l|}{ Opiates } \\
\hline Users & $5(1.9)$ & - & & \\
\hline Non users & $260(98.1)$ & $129(100)$ & 2.47 & 0.14 \\
\hline
\end{tabular}

Table 5. Relationship between current specific substance use and marital status of respondents.

\begin{tabular}{|c|c|c|c|c|}
\hline \multirow[t]{2}{*}{ Substance } & \multicolumn{2}{|c|}{ Marital status } & \multicolumn{2}{|c|}{ Statistics test } \\
\hline & Single & Married & $X^{2}$ & P. Value \\
\hline Tobacco & n (\%) & n (\%) & & \\
\hline Users & 13 (28.9) & $63(18.1)$ & & \\
\hline Non users & $32(71.1)$ & $286(81.9)$ & 3.01 & 0.067 \\
\hline \multicolumn{5}{|l|}{ Stimulant } \\
\hline Users & $10(22.2)$ & 37 (10.6) & & \\
\hline Non users & 35 (77.8) & $312(89.4)$ & 5.12 & $0.028^{*}$ \\
\hline \multicolumn{5}{|l|}{ Cannabis } \\
\hline Users & $7(15.6)$ & $8(2.3)$ & & \\
\hline Non users & 38 (84.4) & 341 (97.7) & 5.12 & $0.028^{*}$ \\
\hline \multicolumn{5}{|l|}{ Inhalants } \\
\hline Users & $5(11.1)$ & $3(0.9)$ & & \\
\hline Non users & 40 (88.9) & 346 (99.1) & 21.06 & $0.001^{*}$ \\
\hline \multicolumn{5}{|l|}{ Opiates } \\
\hline Users & 3 (6.7.) & $2(0.6)$ & & \\
\hline Non users & 42 (93.3) & 347 (99.4) & 11.82 & $0.012^{*}$ \\
\hline
\end{tabular}

Note: ${ }^{*}=$ Significant statistics.

and stimulants $\left(X^{2}=5.12, P=0.028\right)$ were more likely to be used by single respondents compared to those who were married.

Table 6 shows the relationship between some parental characteristics of respondents and respondents current 
psychoactive substance use. Seventy one out of seventy seven (92.2\%) of the respondents who currently use psychoactive substances had mothers who were alive compared to 220 (69.4\%) of non-psychoactive substance users. This difference is statistically significant $\left(X^{2}=16.69, P<0.001\right)$. Almost $7 \%$ of the respondents who currently use psychoactive substances had fathers who were still using tobacco compared to $2.0 \%$ of the non-psychoactive using participants $\left(X^{2}=4.28, P=0.04\right)$.

Table 7 shows the spearman's correlation between current substance use status and sociodemograhic characteristics of the respondents. Negative correlation was obtained between age, marital status and substance use status at $95 \%$ confidence interval and at $99 \%$ confidence interval respectively.

\section{Discussion}

In this study, the younger age groups (22 - 35 years) were found to be more likely to use psychoactive substances compared to those who were older than 35 years. This is in agreement with other studies done among commercial motorcyclists in Zaria, north western Nigeria and Nnewi, south eastern Nigeria [23] [24]. However, it differs from a study in southwestern Nigeria among refugees from Liberia, where respondents in the age group (31 to 40 years) used psychoactive substances more than the younger age group of 18 to 30 years [25]. The socio-cultural differences between Nigeria and Liberia may explain the observed difference.

All the participants in this study were males because only males operate commercial motorcycles in Kano state. Studies have shown that males are more likely to abuse drugs compared to females [3] [23].

All the respondents were Moslems, which is the predominant religion in Kano state. Majority of the respondents participated regularly in their religious activities, which may partly account for the low prevalence of psychoactive substance use in them. This is consistent with the findings of similar studies in Ilorin and Abeokuta

Table 6. Relationship between some parental characteristics and respondent's current substance use.

\begin{tabular}{|c|c|c|c|c|}
\hline \multirow[t]{2}{*}{ Variable } & \multicolumn{2}{|c|}{ Drug use } & \multicolumn{2}{|c|}{ Statistics test } \\
\hline & Users & Non users & $X^{2}$ & $P$. Value \\
\hline Father alive & n (\%) & n (\%) & & \\
\hline Yes & $41(53.2)$ & $149(47.0)$ & & \\
\hline No & $36(46.8)$ & $168(53.0)$ & 0.97 & 0.19 \\
\hline \multicolumn{5}{|l|}{ Mother alive } \\
\hline Yes & $71(92.2)$ & $220(69.4)$ & & \\
\hline No & $6(7.8)$ & 97 (30.6) & 16.69 & $<0.001^{*}$ \\
\hline \multicolumn{5}{|c|}{ Father smoking cigarette } \\
\hline Yes & $5(6.5)$ & $6(2.0)$ & & \\
\hline No & $72(93.5)$ & $294(98.0)$ & 4.36 & $0.04^{*}$ \\
\hline \multicolumn{5}{|c|}{ Father drinking alcohol } \\
\hline Yes & - & $3(1)$ & & \\
\hline No & $77(100)$ & $298(99.0)$ & 0.77 & 0.37 \\
\hline
\end{tabular}

Note: ${ }^{*}=$ Significant statistics.

Table 7. Correlation between respondents’ sociodemographic characteristics and current substance use status.

\begin{tabular}{ccc}
\hline & Spearman's correlation coefficient & \\
\hline Variable & Rho $(\ell)$ \\
\hline Age & $-0.074^{*}$ \\
Marital status & $-0.131^{* *}$ \\
Educational level & 0.51 \\
\hline
\end{tabular}

Note: ${ }^{*}=P<0.05 ;{ }^{* *}=P<0.01$. 
where significant association was found between substance use and religiosity, with those who were very religious being less likely to use psychoactive substances [3] [14]. It is also consistent with the finding of inverse relationship between substance use and religiosity [3] [14] [26].

More than $88 \%$ of the respondents were married, and more than $60 \%$ had between one and 5 children, in keeping with the study in Ilorin among long distance drivers with more than $95 \%$ of the subjects married with children [26]. It would seem that marriage had a moderating effect on substance use by the respondents, as use of cannabis, stimulants, inhalants and opiates was more among the respondents who were single. This is line with a study among 62 patients who use/abuse psychoactive substances, at the drug abuse unit of the Federal Neuropsychiatric Hospital, Aro, Abeokuta, where it was observed that the patients were mostly single [27]. This finding also corroborates a study by Ansari-Moghaddam et al. in Iran which found that singles were twice more likely to use substances compared to those who were married [28].

Most of the participants in this study had some form of education, up to secondary school, which is consistent with the study in Ilorin and Zaria where more than $68 \%$ had some form of education ranging from primary to tertiary education [23] [26]. Participants with lower levels of education reported more substance use compared to those with higher levels of education. This is in line with a study by Ansari-Moghaddam et al. that showed the association between substance use and education [28]. They found that those with higher levels of education were less likely to initiate, and were more likely to stop substance abuse compared to those with lower levels of education.

On the whole the parental background of the respondents can be described as fairly stable with more than half still having both parents alive. Having a smoking father was statistically related to respondents substance use. This finding agrees with many studies which reported the strong influence of parental and sibling's exposure on psychoactive substance use [29]-[33].

This study is limited by the fact that a causal relationship cannot be established between psychoactive substance use and socio-demographic characteristics of the participants due to the nature of the study design. However, as a pioneer study in Kano, North Western Nigeria, this should serve as a baseline for future studies to explore the causality of socio-demographic factors and psychoactive substance use.

\section{Conclusions}

This study found that being of younger age, being single, and having a father who smoked were significantly associated with psychoactive substance use.

Participants who were singles were more likely to use inhalants, opiates, cannabis and stimulants. No relationship was observed between the age of the respondents and specific substance use.

Legislations should be enacted to reduce the rate of psychoactive substance use among motorcycle operators and general population at large.

\section{Acknowledgements}

We wish to acknowledge the registered motorcycle operators under ACOMORAN for their time. We also wish to acknowledge AKTH management for providing support and permission for this research. We also thank Prof's Richard Uwakwe and Owodoiho Udofia for their efforts towards the success of this research.

\section{Conflicts of Interest}

The authors did not declare any conflict of interest for this study.

\section{Authors Contributions}

ZGH designed the study and also supervised data collection. MIG reviewed the literature and did data analysis and wrote the discussion. Both authors proof read the final manuscript of the article.

\section{References}

[1] United Nations Drug Control Programme (2006) Country Profile on Nigeria. www.unodc.org/unodc/undcp

[2] Suleiman, G.T., Adeyemi, S.O. and Adeponle, A.B. (2006) An Overview of Psychoactive Substance Use and Misuse 
in Northern Nigeria. Nigerian Journal of Psychiatry, 4, 9-19.

[3] Gureje, O., Degenhardt, L., Olley, B., Uwakwe, R., Udofia, O., Wakil, A., Adeyemi, O., Bohnert, K.M. and Anthony, J.C. (2007) A Descriptive Epidemiology of Substance Use and Substance Use Disorder in Nigeria during the Early 21st Century. Drug and Alcohol Dependence, 91, 1-9. http://dx.doi.org/10.1016/j.drugalcdep.2007.04.010

[4] Kontula, O. (1995) The Prevalence of Drug Use with Reference to Drug Use in Finland. The International Journal of Addictions, 30, 1053-1066.

[5] National Institute on Drug Abuse (1991) National Household Survey on Drug Abuse: Highlights. Government Printing Office, Washington DC.

[6] Jaffe, M. (1995) Amphetamine Use in USA. The International Journal of Addiction, 30, 856-990.

[7] ICNB Annual Report (2004) Vienna, Austria.

[8] Lamina, S. and Subramanian, M.B. (2009) Khat (Catha edulis): Academic, Health and Psychosocial Effects on "Mature” Students. African Journal of Drug and Alcohol Studies, 8, 49-57.

[9] Ahmed, M.H. (1986) Drug Abuse as Seen in the University Department of Psychiatry, Kaduna, Nigeria, in 1980-1984. Acta Psychiatrica Scandinavica, 74, 98-101. http://dx.doi.org/10.1111/j.1600-0447.1986.tb06234.x

[10] Lambo, T.A. (1960) Further Neuro-Psychiatric Observation in Nigeria. British Medical Journal, II, 1696-1714. http://dx.doi.org/10.1136/bmj.2.5214.1696

[11] Asuni, T. (1964). Socio-Psychiatric Problem of Cannabis in Nigeria. U.N. Bulletin on Narcotics, 16, 17-28.

[12] Adelekan, M.L., Abiodun, O.A. and Obayan, R.O. (1992) Prevalence and Pattern of Substance Use among Undergraduate in a Nigerian University. Drug and Alcohol Dependence, 29, 255-261. http://dx.doi.org/10.1016/0376-8716(92)90100-Q

[13] Adelekan, M.L. and Odejide, O.A. (1989) The Reliability and Validity of the WHO Student Drug Use Questionnaire among Nigerian Students. Drug and Alcohol Dependence, 24, 245-249. http://dx.doi.org/10.1016/0376-8716(89)90062-8

[14] Akinhanmi, O.A. (1996) Drug Abuse among Medical Student in a State University in Nigeria. A Dissertation Submitted to West African College of Physicians.

[15] Nevadomsky, J. (1982) Self Reported Drug Use among Secondary School Students in Two Rapidly Developing Nigeria Towns. Bulletin of Narcotics, 34, 21-32.

[16] Vazquel, F.C. (2010) Psychoactive Substance Use and Dependence among Spanish University Students: Prevalence, Polyconsumption and Comorbidity with Depression. Psychology Research, 106, 247-313.

[17] Mason, M., Cheung, I. and Walker, L. (2004) Substance Use, Social Networks and the Geography of Urban Adolescents. Substance Use and Misuse, 39, 1751-1777.

[18] Centre for Disease Control and Prevention (2008) Web-Based Injury Statistics Query and Reporting System. National Centre for Injury prevention and Control.

[19] Substance Abuse and Mental Health Services Administration (2009) National Survey on Drug Use and Health. Office of Applied Studies.

[20] Kalula, T.A. (2011) Cannabis Use among Young People in Dar-es-salam, Tanzania: A Qualitative Study. African Journal of Drug and Alcohol Studies, 10, 29-39.

[21] Adebiyi, A.O., Faseru, B., Sangowawa, A.O. and Owoaje, E.T. (2010) Tobacco Use amongst out of School Adolescents in a Local Government Area in Nigeria. Substance Abuse Treatment, Prevention, and Policy, 5, 24. http://dx.doi.org/10.1186/1747-597X-5-24

[22] Smart, R.G., Hughes, P.H. and Johnson, L.D. (1980) A Methodology for Student Drug Use Surveys. WHO, Geneva.

[23] Alti-Muazu, M. and Aliyu, A.A. (2008) Prevalence of Psychoactive Substance Use among Commercial Motorcyclists and Its Health and Social Consequences in Zaria, Nigeria. Annals of African Medicine, 7, 67-71. http://dx.doi.org/10.4103/1596-3519.55678

[24] Adogu, P.O.U., Illika, A.L. and Asuzu, A.L. (2009) Predictors of Road Traffic Accidents, Road Traffic Injury and Death among Commercial Motorcyclists in an Urban Area of Nigeria. Nigerian Journal of Medicine, 18, 393-397.

[25] Amosu, S.M. (2008) Drug Abuse: A Community Sample of Refugees at Oru Camp, Abeokuta. Dissertation, National Postgraduate Medical College of Nigeria, Lagos.

[26] Makanjuola, B.A., Oyeleke, S.A. and Akande, T.M. (2007) Psychoactive Substance Use among Long Distance Vehicle Drivers in Ilorin, Nigeria. Nigerian Journal of Psychiatry, 5, 14-18.

[27] Adamson, T.A., Onifade, P.O. and Ogunwale, A.O. (2010) Trends in Socio Demographic and Drug Abuse Variables in Patients with Alcohol and Drug Use Disorders in a Treatment Facility. West African Journal of Medicine, 29, 12-18.

[28] Ansari-Moghaddam, A. (2012) Predictors of Initiation, Continuation and Transition of Drug Use in South-Eastern Iran. 
Journal of Pakistan Medical Association, 62, 698-703.

[29] Yisa, I.O. and Fatiregun, A.A. (2007) Pattern of Substance Use among Senior Students of Command Secondary Schools in Ibadan, Nigeria. Nigerian Journal of Medicine, 18, 286-294.

[30] Okoza, J., Aluede, O., Fajoju, S. and Okhiku, I. (2009) Drug Abuse among Students of Ambrose Alli University, Ekpoma, Nigeria. European Journal of Social Sciences, 10, 85-92.

[31] Ndaguye, M.N. (2010) The Sociological Implications of Drug Abuse among Nigerian Youth: Who Is to Blame. Drug Free Club CDs, NYSC, Birnin Kebbi.

[32] Abasiubong, F., Atting, I. and Bassey, E. (2008) A Comparative Study of Use of Psychoactive Substances amongst Secondary Schools Students in Two Local Government Areas of Akwa Ibom State, Nigeria. Nigerian Journal of Clinical Practice, 11, 45-51.

[33] Oladeji, B.D., Makanjoula, V.A. and Gureje, O. (2010) Family-Related Adverse Childhood Experiences as Risk Factors for Psychiatric Disorders in Nigeria. British Journal of Psychiatry, 196, 186-191. http://dx.doi.org/10.1192/bjp.bp.109.063677 